\title{
The View from City Hall: Local Perceptions of Intergovernmental Fiscal Relations in the Czech Republic
}

Scott M. Smith

Phillip J. Bryson

Gary C. Cornia

Follow this and additional works at: https://scholarsarchive.byu.edu/facpub

Part of the Economics Commons

\section{Original Publication Citation}

Scott M. Smith, Phillip J. Bryson and Gary C. Cornia, "The View from City Hall: Local Perceptions of Intergovermental Fiscal Relations in the Czech Republic," Communist and Post-Communist Studies, forthcoming. http://www.journals.elsevier.com/communist-and-post-communiststudies/

\section{BYU ScholarsArchive Citation}

Smith, Scott M.; Bryson, Phillip J.; and Cornia, Gary C., "The View from City Hall: Local Perceptions of Intergovernmental Fiscal Relations in the Czech Republic" (2011). Faculty Publications. 89.

https://scholarsarchive.byu.edu/facpub/89 
The View from City Hall:

Local Perceptions of Intergovernmental Fiscal Relations in the Czech Republic

Scott M. Smith

Phillip J. Bryson

Gary C. Cornia

Brigham Young University

Corresponding Author:

Phillip J. Bryson

Driggs Professor of Economics

Marriott School

Brigham Young University

Provo, Utah

Tel: 801-422-2526

Email: phil_bryson@byu.edu 


\section{The View from City Hall:}

\section{Local Perceptions of Intergovernmental Fiscal Relations in the Czech Republic}

\section{Introduction}

Since the economic transition began in Central and Eastern Europe in 1990, fiscal decentralization has been viewed by many scholars as an essential component of democratic development. Intergovernmental fiscal relations should reflect the process of decentralization over time, which implies growing autonomy for subnational governments. The whole process is intended to overcome the extreme centralization of the planning system of the previous era and is the primary means of ensuring the efficiency of public services (Tanzi, 1991; Litvack, Bird and Ahmand, 1998). Decentralization elicits support from the public finance, public choice, and public management literatures (Tiebout, 1956; Bish and Kirk, 1974) because it brings transparency and accountability to public decision and permits broad participation of the citizenry (Oates, 1998).

The general contemporary image of the Czech Republic is that of a country engaged in an extended public sector transition from the central planning era. But old habits die hard and the high degree of centralism of that period was deeply ingrained. Consequently, we continue to find in our encounters with the Czech Republic some of the characteristics of a substantially centralized fiscal system - with transfers from the center representing a large share of the total revenues of local budgets and at the local level, low local fiscal effort and very meager ownsource revenue generation.

The limited degree of fiscal decentralization actually achieved in the Czech Republic is dismissed by some with the observation that a centralist posture is not that damaging. There is also the contention that centralism in the Czech Republic (and a number of other similar countries in the region) is not extreme. But an appropriately common question is why economic and fiscal decentralization have been slow (Bahl, 2007). In this article we avoid that line of questioning, preferring to illuminate the views of local officials with respect to decentralization. We consider whether the people most directly affected by decentralization efforts (or the lack of such efforts), the local Czech officials in the trenches, feel that centralist tendencies are a problem and also the extent to which those officials have supported fiscal decentralization.

While the process of transition from centralized to autonomous governments is an important focus of the literature on fiscal decentralization, specific documentation of the experience of local officers has been lacking in the literature. It is important to know how local 
officials perceive the issues of fiscal decentralization and inter-governmental fiscal relations in the Czech Republic.

Looking specifically at the Czech case, Kameničková (1996), then of the Finance Ministry, perceived a “discord” in local budgets between the municipality's authority on the expense side, which in her view was rather high, and on the income side, which she viewed as very limited. But we found the reality less positive than Kameničková would have it. We felt it true that Czech local authorities have basically no power to affect their budget revenues, but it is a stretch to imply that they have had considerable expenditure-side authority, since they have no significant independent revenue sources and live on transfers and grants which historically have often mandated expenditures. The lack of independent sources of revenue for the Czech subnational governments and the center's inclination to watch out for small local governments lacking the resources adequately to provide for their own management have resulted in a fiscal system that has scarcely accommodated fiscal decentralization. That the municipal governments of the Czech and Slovak Republics had enjoyed little autonomy from 1989 to about 2000 has been documented by Joao do Carmo Oliveira and Jorge Martinez-Vazques (2001) and by Bryson and Cornia (2000). We had the impression that socialist and developmental legacies lingering in the transition era have accommodated the previous centralist traditions and that there has been an inclination to retain a good deal of central directive control. We therefore hypothesized that a survey of local officials would reveal perceptions of intergovernmental relations that would provide important insights.

The paper proceeds as follows. Section II reviews the research design of the questionnaire and the underlying hypotheses. We begin by scaling cities according to the perceived autonomy of survey respondents. We extend the analysis of autonomy in Section III by calculating factor scores for survey respondents on each of the fiscal management dimensions, clustering them to identify groupings reporting similar styles of autonomous government. By cross-tabulating respondent autonomy profiles with key descriptive variables, municipalities are profiled in a manner susceptible to more vivid interpretation. Section IV profiles the segments of the high- and low-autonomy groups, extending the analysis by examining budget expenditures according to the new measures of autonomy. Section V investigates municipal expenditures of diverse types as financed by different funding sources. Here we find that city size explains those expenditures better than autonomy segments can. In the final section we offer summary and conclusions. 


\section{II.The Research Design}

\section{Instrument Development and Data Collection}

As we interviewed and discussed intergovernmental fiscal relations with central and local financial officers, we began to assemble a set of questions about the practices and perceptions that seemed to most directly affect intergovernmental relations. These gradually became a questionnaire for local officials. It was developed in cooperation with officials of The Union of Towns and Municipalities of the Czech Republic (Svaz měst a obcí České republiky, or SMO). As the questionnaire took form, the SMO offered input during the multiple pre-tests that were used to fine tune the questionnaire. The questionnaire was targeted for local officials, mayors and professional administrators, and was designed to identify local perceptions and preferences of autonomy, and actual practices. The questionnaire was administered online in Czech through Qualtrics.com. By the cutoff date, January 15, 2006, a total of 456 Czech municipal officials, most of whom were elected mayors, had completed the questionnaire.

The high return rate may be a result of (1) the publicity received through the Office of the Union of Towns and Municipalities in the Czech Republic, (2) the personalized handling of the outgoing invitation by SMO, and (4) significant respondent interest in the topic.

We gain little insight from the literature into differences between municipalities reporting lower or higher autonomy in their activities, so we enjoyed little help in developing hypotheses about the variables of greatest influence on local perceptions of autonomy. Our interaction with public officials at all levels did give us some ideas about diverse attitudes and viewpoints. These led to the formulation of the following hypotheses:

$\mathrm{H}_{1} \quad$ Czech municipalities operating with perceptions of high levels of autonomy, are characterized as having (a) larger populations, (b) larger budgets, and (c) more resources to self manage

Although these hypotheses lack a priori data about the directionality or specificity of outcomes, it seems clear that one key to understanding municipality governance and autonomy is to understand the experiences and spending patterns of the municipalities involved. Next, given that high and low autonomy municipalities are identified, we hypothesize that:

$\mathrm{H}_{2} \quad$ High and low autonomy municipality groups are each composed of multiple segments, whose members respond differently to their individual municipal situations. 
Likewise,

$\mathrm{H}_{3} \quad$ High and low autonomy groups differ in their use of financial funding by type of municipal expenditures and funding source.

\section{Development of the Autonomy Scale}

Governmental and administrative autonomy is defined as the ability of a municipality to make financial decisions independently of the central government. This multi-dimensional construct measuring this financial autonomy is made up of five independent measures, each scaled on a 5 point agreement scale (see Exhibit 1):

The relationship is straightforward. Autonomy is the sum of five other variables.

Autonomy is equal to investments (capital investments in local facilities) plus debt (the ability to meet debt obligations), plus fund management discretion (independently managing and transferring funds from various sources to cover cost increases and over-runs), plus local Control (the ability to use local discretion to pool and allocate funds to various projects) plus local revenue(the percentage of total revenue generated locally. ${ }^{1}$

These independent measures go beyond the typical measure of decentralization considering only the percent of self-generated revenue. In constructing an additive, multi-item scale, it is critical that these measures are mutually independent. That independence is demonstrated by near-zero intercorrelations shown in Table 1.

The additive scaling procedure produced a normally distributed scale with mean of 10.54 and standard deviation of 2.53 that ranged from 2.55 to 18.55. For the purpose of later analysis, evenly sized tertile groups were identified for "Low Autonomy" ( $<9.3)$, comprising 32.0\% of all municipalities, “Medium Autonomy” (9.31 - 11.55), comprising 33.8\% of all municipalities, and “High Autonomy” (11.55 - 18.55), comprising 34.1\% of all municipalities. The distribution of the autonomy measure is shown in Figure 1.

Two self-reported measures of autonomy were correlated with the autonomy scale: Q1: “Although our municipality receives most of our revenue from the central government, we operate with autonomy”, and Q9: “Although we face many required expenditures, we still have enough funds to make me feel we have budget autonomy and discretion.” But the high levels of autonomy reported by Czech town and city managers diverge substantially from our expectations. Czech local officers operate with substantial autonomy relative to their former

Table 1 about here 
situation under centralized government practices, but their actual autonomy is not nearly so great when compared to that enjoyed by western governments.

This becomes apparent when we observe that a bare majority (52\%) of respondents recognized that the source of funds can affect the autonomy of the unit receiving them. Many agreed that revenues from a locally designed and planned property tax would be of greater worth

Figure 1 about here

than an equal amount of funds transferred from the center (since it can be presumed that such funds would not as likely be encumbered by central spending mandates). The detailed responses to these and similar questions are provided in Exhibit 1.

\section{Identifying Autonomy and Governmental Management Styles}

Following the segmentation of city and town administrators into autonomy tertiles, a factor analysis condensed the large number of measures descriptive of governmental operations into a smaller set of factors representing dimensions of fiscal management. This analysis made it possible to profile the most common governance issues.

Factor scores were calculated for each respondent to show the municipality's score on each of the fiscal management dimensions. Finally, these factor scores were clustered to identify groupings of municipalities reporting similar styles of autonomous government- again, within the high and low autonomy groups. Once the autonomy profiles were developed, a simple procedure was used to bring the entire analysis to a focus. By cross-tabulating respondent autonomy profiles with key descriptive variables, municipalities could be profiled in a more interpretable way.

\section{Integrating Autonomy and Experiential Fiscal Management Measures}

The major aim of measuring actual fiscal practices that were adopted during decentralization is to construct recognizably human portraits of municipal governance activities. Decision making measures useful in evaluation can seem more like demographic than managerial measures (e.g., "Our municipality always has sufficient funds to accomplish the tasks expected of us”). Others may tap deeper levels (e.g., "It seems logical to me that as in England or in the United States, a real estate tax, effectively designed and administered, could be a source of considerable revenue for local governments”). Although the present study includes some measures like the preceding, most specifically reflect the management of expenditures and 
programs (e.g., “The central and/or regional governments supply no public services that would be better to supply through independent, local governments”).

Respondents were asked to indicate the extent to which they agreed with the items in Exhibit 1, using a five-point scale (1 = “Strongly Disagree,” 5 = "Strongly Agree”). Readers should note that the attributes with the highest levels of agreement indicate the governance issues having the greatest influence on municipal governance in the Czech Republic.

Table 2 reports the factors and loadings (the correlations between the individual decisional items and the underlying factor ) for these 14 decisional items. Towns and Cities were first factor analyzed separately on these items to examine differences by municipality size. But the results based on municipality size were so similar as to deserve the same factor labels. Therefore, a single combined factor solution for the towns and cities was finalized. A number of solutions, each with a different number of factors were examined, and in the end a scree-plot approach (which explains factors and variances) was used to determine the optimal number of factors for each of these analyses. The key factors that serve as satisfiers and dissatisfiers for municipal fiscal decision making are the following:

Factor 1 Advantages of Locally Implemented Property Tax

Factor 2 Sufficient Funding

Factor 3 Revenue Autonomy

Factor 4 Dependence on Central Government

Factor 5 Spending Autonomy

Each is a factor shown in bold in the headings of Table 3 and accompanied by associated

Table 2 about here

measures - characteristics that respondents perceive as being related to each other and to the factor. Successful municipalities are more likely to have the most positive performance, or the least negative performance, on these factors.

Following the identification of the factors, respondent scores on each factor were developed using Anderson-Rubin coding (which produces a factor-score mean $=0$ and standard deviation $=1$ ). These scores are illustrated in Figure 2 for low autonomy vs. high autonomy municipalities.

The vertical axis of Figure 2 conveys important scaling information. The center point of the chart equals a value of -.75, and values at the midpoint of each axis are the mean value of 0.0. The scale points on each of the five axes reflect the number of standard deviations from the average of each factor.

Figure 2 about here 
Figure 2 illustrates graphically that municipality operating procedures vary greatly by municipality autonomy groupings. Statistical tests of the differences in factor score means for the three autonomy groups were conducted by one-way analysis of variance (ANOVA, see Table 3). With the exception of Factor 1: Advantages of a Locally Implemented Property Tax, the differences between the three autonomy groups were all statistically significant. Associated post-hoc multiple comparisons tests were also conducted between all group means on all factors (analyzing statistical differences between the red, green and blue lines in Figure 2 for each axis). All differences were statistically significant except four: Factor 1: high vs. med and low vs. medium; Factor 4: high vs. medium; Factor 5: medium vs. high.

\section{Table 3 about here}

\section{Profiling the Municipal Autonomy Segments}

$\mathrm{H}_{2}$ predicted that neither high autonomy municipalities nor low autonomy municipalities comprised a single segment. To test this hypothesis, a cluster analysis of respondent factor scores was conducted within each autonomy group using the k-means cluster analysis procedure. Separate cluster analyses were completed for the low autonomy and the high autonomy groups. After examining several clustering solutions for each group, solutions were reached that met the criteria of each cluster or segment being: (1) substantial in size, (2) clearly differentiated from other segments, (3) internally consistent in characteristics and (4) interpretable. This analysis identified three segments among low autonomy municipalities, and another three segments among high autonomy municipalities. The segments were named on the basis of their prevailing factor loadings.

To visually summarize the segments on their fiscal administrative style measures, the average factor scores were plotted for each segment. See Figure 3a for the low autonomy municipalities and Figure 3b for the high autonomy municipalities. Again, the values of 0 on the charts' vertical axes are the average of the municipality profiles. Numbers higher or lower than 0 reflect the number of standard deviations of segment's average factor score versus the average group score for that factor. Statistically significant differences $(\mathrm{p}<.05$ for each factor) between four of the five factors were found for the low autonomy municipalities (Figure 3a), and for the high autonomy municipality segments (Figure 3b). The “property tax" factor, a set of hypothetical statements about the desirability of a locally administered property tax was not significant. This finding is not unexpected in that this potential source of revenue was more 
equally desired by all groups. In total, this analysis reveals important differences within each major group, and is considered to support $\mathrm{H} 2$.

Next, we will attend to the governmental implications of each segment for government planners. These findings suggest that an analysis by autonomy segment can have large implications for governmental practice. Included in the following discussion is a short listing of fiscal management descriptives of each segment. Data for the 14 fiscal management measures were standardized and sorted high-to-low for each segment. The top five items are reported for each of the six segments.

\section{The Low-Autonomy Segments}

Dependencity. “Dependencity” represents 10.2\% of all respondents (in all 6 municipality segments), or $25 \%$ of the three low autonomy municipalities. Although it is the second largest of the segments, this segment of large city respondents does not percieve itself as being autonomous either in its ability to spend or to generate revenue. It is dependent on the central

\section{Dependencity administrators agree with statements that:}

- Our municipality could operate with much greater autonomy if we were not so dependent upon financial transfers from the central government to fund our activities.

- The debt burden of our local self-government is appropriate and payments of principal and interest during the repayment period do not cause significant problems with fulfillment of financial obligations which accrue to us by extant legal norms.

\section{and disagree with the statements:}

- In my experience, no mandates from the central government have been given unless public moneys were transferred to fund them.

- In making budgetary decisions, we pool all revenue sources to determine the total amount available for all expenditures, and then we spend the entire pool on activities and projects according to our own discretion.

- In making budgetary decisions, we pool all revenue sources to determine the total amount available for all expenditures, and then we spend the entire pool on activities and projects according to our own discretion.

- Although we face many required expenditures, we still have enough funds to make me feel that we have budget autonomy and discretion. 


\section{Littleton administrators agree with statements that:}

- In making budgetary decisions, we pool all revenue sources to determine the total amount available for all expenditures, and then we spend the entire pool on activities and projects according to our own discretion.

- Although our municipality receives most of our revenues from the central government, we operate with complete autonomy.

- Our municipality could operate with much greater independence if we were not so dependent upon financial transfers from the central government to fund our activities.

\section{And disagree with statements like:}

- Our municipality always has sufficient funds to accomplish the tasks expected of us.

government for funding, which it believes to be adequate. Consistent with other low autonomy municipalities, this segment receives an average of $66.9 \%$ of revenues from the central government, but is similar to the Dependent Autonomy segment in terms of the size of municipalities represented.

These municipalities are dependent upon the financial transfers from the central government to fund their activities, but feel that they are underfunded and have little discretion as to how to allocate their resources.

Littleton. Littleton represents $24.7 \%$ of all respondents and $60.3 \%$ of those from the low autonomy municipalities. Though this is the segment with municipalities having the smallest resident populations, the total number of municipalities is significant.

Municipalities in this segment are best described as moderate in their outlook toward all aspects of management. They are most like the similarly balanced Prosperityville segment, but have a consistently lower evaluation on all autonomy and dependency measures. There are no real deficiencies evidenced in their ratings, but they nevertheless believe they are underfunded and are dependent on central government funding. Littleton, because of the small population base, is not provided with adequate funding for the level of services available in larger cities. 
Middleton. Middleton represents $6 \%$ of all muncipalities and $14.7 \%$ of the low autonomy segment. Though this is the smallest segment in terms of the number of

\section{Middleton municipalities show strong agreement with statements that:}

- In making budgetary decisions, we pool all revenue sources to determine the total amount available for all expenditures, and then we spend the entire pool on activities and projects according to our own discretion.

- From all financial resources, we receive at least enough revenue to cover annual operating costs.

- The central and/or regional governments supply no public services that would be better to supply through independent, local governments.

- Revenues from a property tax planned and designed by local self-governments would have a higher value than the same amount of shared-tax revenues from the central government..

\section{And disagree with statements that:}

- If expenses for one function, e.g., social care, increased rapidly, we could meet those costs by spending less for one or more other functions, e.g., education, sport, culture or transportation, according to our own preferences.

- In my experience, no mandates from the central government have been given unless public moneys were transferred to fund them.

municipalities, it is a very important group that represents struggling, small-sized towns that are not yet cities. This segment is the most vocal about their dependence on financial transfers and revenue autonomy, but it struggles with spending autonomy and the mandates that are associated with funding.

Middletown is associated with minimal spending autonomy, anticipation of locally administered property taxes sometime in the future, and of ultimately achieving funding and revenue autonomy.

\section{The High Autonomy Segments}

Independencity. Independencity represents $27.5 \%$ of the high autonomy municipalities and $16.3 \%$ of all municipalities. This is the smallest high autonomy segment, but it represents cities of average population. When compared to other high autonomy segments, it is characterized by the highest levels of revenue autonomy and sufficiency of funding, and lowest 
level of dependency on the central government. Suffiency of funding, while highest for all segments, is still low in absolute terms, indicating a general inadequacy of funding across all

\section{Independencity managers strongly agree with the statements that,}

- Our municipality always has sufficient funds to accomplish the tasks expected of us.

- In the past ten years, funds we have received from all sources have permitted us to make investments in capital facilities that will enable us to provide necessary functions such as schools, social services, and garbage collection, at a satisfactory level in the future.

- Although we face many required expenditures, we still have enough funds to make me feel that we have budget autonomy and discretion.

- In making budgetary decisions, we pool all revenue sources to determine the total amount available for all expenditures, and then we spend the entire pool on activities and projects according to our own discretion.

- From all financial resources, we receive at least enough revenue to cover our annual operating costs

Czech municipalities. Although Independencity municipalities report low spending autonomy, reflective of the mandates that accompany funding. Independencity represents cities that focus on generation of alternative revenue sources, reducing dependency on the central government as a source of revenues.

Prosperityville. Prosperityville represents the largest population segment, being composed of a larger group of average-sized cities. It accounts for $40 \%$ of high autonomy municipalities and $24.1 \%$ of all municipalities. Prosperityville respondents are well balanced across all factors, perceiving high levels of sufficient funding and spending autonomy. 


\section{Officials of prosperityville agree with statements that,}

- Although we face many required expenditures, we still have enough funds to make me feel that we have budget autonomy and discretion.

- In the past ten years, funds we have received from all sources have permitted us to make investments in capital facilities that will enable us to provide necessary functions such as schools, social services, and garbage collection, at a satisfactory level in the future.

- $\quad$ Our municipality always has sufficient funds to accomplish the tasks expected of us.

- If expenses for one function, e.g., social care, increased rapidly, we could meet those costs by spending less for one or more other functions, e.g., education, sport, culture or transportation, according to our own preferences.

\section{And disagree that,}

- In my experience, no mandates from the central government have been given unless public moneys were transferred to fund them.

The Prosperityville segment appears to represent a group of municipalities for which the balance of government funding, revenue and spending autonomy is working. Adequate funding appears to provide the necessary means for making capital investments to improve the municipal infrastructure.

Autonomous Dependencity. Autonomous Dependencity represents 31.6\% of the high autonomy municipalities and $18.7 \%$ of all municipalities. The largest cities are found in this group. Autonomous Dependencity is characterized by a perception of revenue and spending autonomy, combined with central governement dependency. Their views may reflect an intergovernmental fiscal schizophrenia as distinct as the title of the group. Funding is believed by Autonomous Dependencity officials to be insufficient. 


\section{Autonomous Dependencity municipal officials of these cities agree with statements:}

- In making budgetary decisions, we pool all revenue sources to determine the total amount available for all expenditures, and then we spend the entire pool on activities and projects according to our own discretion.

- Our municipality could operate with much greater independence if we were not so dependent upon financial transfers from the central government to fund our activities.

\section{And disagree with statements that,}

- In my experience, no mandates from the central government have been given unless public moneys transferred to fund them.

- $\quad$ Our municipality always has sufficient funds to accomplish the tasks expected of us.

- In the past ten years, funds we have received from all sources have permitted us to make investments in capital facilities that will enable us to provide necessary functions such as schools, social services, and garbage collection, at a satisfactory level in the future.

Autonomous Dependencity looks toward the central government for funding, and interestingly, places the lowest value on the prospect of local property taxes of any of the six segments.

Table 4 reports the similarities and differences across the six segments for the study's non-fiscal decision making style measures. As might be expected, autonomy appears to be more a function of annual receipts and the lack of government funding than population size. Highly autonomous groups maintain a central government revenue percentage int eh 70\% range, whereas low autonomy groups were in the upper $80 \%$ range. Likewise, reported annual receipts were several times larger for the autonomous groups. The source of these differential funds was not reported. As a final note, the largest revenue municipality group, Independent City, reported more city managers than majors, a fact which reflects a more western business approach to city government.

\section{Table 4 about here}

Table 5 provides a final descriptive insight into these autonomy clusters.

Table 5 about here 


\section{Conclusions}

We began with a review of the research design of the questionnaire and the hypotheses underlying the development of that design. The statistical analysis began by scaling cities according to the perceived autonomy of survey respondents. Factor analysis condensed the large number of measures descriptive of governmental operations into a smaller set of factors representing dimensions of fiscal management. Factor scores characterizing respondent perceptions of fiscal autonomy were identified within the high and low autonomy respondent groups. By cross-tabulating respondent autonomy profiles with key descriptive and expenditure variables, the perceptions and choices of respondent groups could be profiled and interpreted. In Section III the autonomy analysis was extended to examine self-reported autonomy levels by municipality size to determine what the size of the municipalities implied about expenditure patterns. A factor analysis incorporated the variables reflective of satisfaction and dissatisfaction on the part of local officials, showing how municipal operating procedures vary by perceptions of municipal autonomy.

Section IV extended the analysis by examining budget expenditures according to these new measures of autonomy. A cluster analysis, based on factor scores for each respondent, was conducted within the high-autonomy and low-autonomy groups. This methodology enabled a colorful and detailed description of the characteristic attitudes and perceptions of the autonomy groups. We concluded that there were six important groups of municipal officials within the overall high- and low-autonomy rubrics. The low-autonomy groups included the perceptions of officials stemming from distinct types, including what we characterized as "Dependencity," "Littleton," and "Middleton." The high-autonomy segments included Independencity," "Prosperityville," and "Autonomous Dependencities."

While this analysis nicely categorized the general attitudes and perceptions of the groups of local officials, attitudes and perceptions were not found to differ statistically by expenditure types. Hardly any of the expenditure types differed across the autonomy segments. That should not be surprising, since the relationship between funding sources and expenditure types should more likely be expected to differ by city size than by self-reported perceptions of the prevailing fiscal situation.

However, the perceptions of autonomy we have been considering, are important for many purposes. The autonomy under discussion is, of course, perceived autonomy. The managers of the smaller municipalities may have a feeling of greater autonomy because there are fewer 
constraints on them and fewer orders to take. This of course corresponds to a lack of resources and the small number of inhabitants requiring public services.

One would generally think of city size as being the basis of autonomy. Cities have access to more financial and human resources and would be expected to require less outside monitoring and management. While city size in some situations affects expenditures, it appears that revenues influence autonomy perceptions. The city officials of differing autonomy segments have varying viewpoints. These views and perceptions appear to reflect and may have an important impact on expenditures. 


\section{Sources}

Bahl, R.W. and J. Martinez-Vazquez, 2007, Sequencing Fiscal Decentralization. World Bank Policy Research Working Paper No. 3914. http://ssrn.com/abstract=917485

Bish, R.L. and Kirk, R.J., 1974, Economic Principles and Urban Economic. Prentice-Hall, Inc., Englewood Cliffs, NJ.

Bryson, P.J. and Cornia, G.C., 2001, Land and Building Taxes in the Republic of Slovakia. In Youngman, J. and Malme, J. (Eds.), The Development of Property Taxation in Economies in Transition: Case Studies from Central and Eastern Europe. The World Bank, Washington, D.C., pp. 51-66.

Bryson, P.J. and Cornia, G.C., 2000, Fiscal decentralisation in economic transformation: The Czech and Slovak cases. Europe-Asia Studies 52 (3), 507-522.

Kameničková, V., 1996, Jak jsou na tom obce v České republice? [The Situation in the Municipalities of the Czech Republic] Prague, Ministěrstvo financi, Czech Republic, November 1996, p. 16.

Litvak, J.I., Bird, R.M., and Ahmand, J., 1998, Rethinking Decentralization in Developing Countries. World Bank, Washington, D.C.

Oates, W.E., 1998, 'Introduction.’ In Wallace E. Oates, (Ed), The Economics of Fiscal Federalism and Local Finance. Edward Elgar Publishing, North Hampton, Mass., pp. xviii, xix.

Oliveira, J.Do C. and J. Martinex-Vazques, 2001, Czech Republic: Intergovernmental Fiscal Relations in the Transition. World Bank, Washington, DC.

Tanzi, V., 1991. Public Finance in Developing Countries. Edward Elger Publishing, Aldershot, England.

Tiebout, C.M., 1956, A Pure Theory of Local Expenditures. Journal of Political Economy, 54 (5), 416-424. 
Figure 3a about here Figure $3 b$ about here 